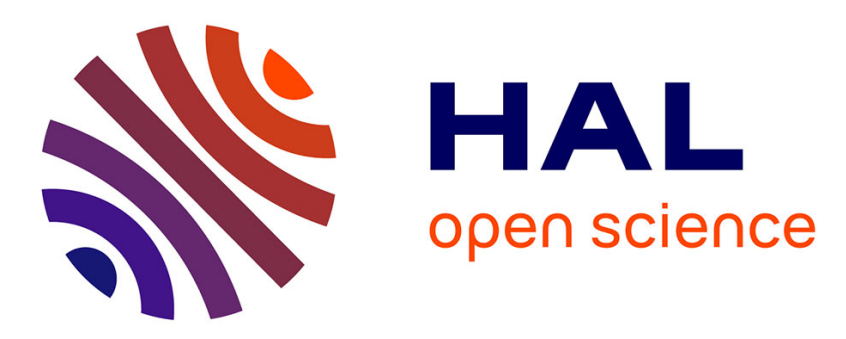

\title{
Strain dependence of the direct energy bandgap in thin silicon on insulator layers
}

\author{
J Munguía, J-M Bluet, H Chouaib, G Bremond, Michel Mermoux, C \\ Bru-Chevallier
}

\section{- To cite this version: \\ J Munguía, J-M Bluet, H Chouaib, G Bremond, Michel Mermoux, et al.. Strain dependence of the direct energy bandgap in thin silicon on insulator layers. Journal of Physics D: Applied Physics, 2010, 43 (25), pp.255401. 10.1088/0022-3727/43/25/255401 . hal-00569631}

\section{HAL Id: hal-00569631 \\ https://hal.science/hal-00569631}

Submitted on 25 Feb 2011

HAL is a multi-disciplinary open access archive for the deposit and dissemination of scientific research documents, whether they are published or not. The documents may come from teaching and research institutions in France or abroad, or from public or private research centers.
L'archive ouverte pluridisciplinaire HAL, est destinée au dépôt et à la diffusion de documents scientifiques de niveau recherche, publiés ou non, émanant des établissements d'enseignement et de recherche français ou étrangers, des laboratoires publics ou privés. 


\title{
Strain dependence of the direct energy bandgap in thin silicon on insulator layers
}

\author{
J. Munguía ${ }^{1}$, J-M. Bluet ${ }^{1}$, H. Chouaib ${ }^{1}$, G. Bremond ${ }^{1}$, M. Mermoux ${ }^{2}$ and C. Bru-Chevallier ${ }^{1}$ \\ 1.- Institut des Nanotechnologies de Lyon (INL), CNRS UMR-5270, Université de Lyon, INSA- LYON, 7, avenue \\ Jean Capelle, Bât. Blaise Pascal, 69621 Villeurbanne, France. \\ 2.- Laboratoire d'Electrochimie et de Physico-chimie des Matériaux et des Interfaces, UMR 5631, (INPG- \\ CNRS), BP75, 38042 Saint Martin d'Hères Cedex, France. \\ E-mail jean-marie.bluet@insa-lyon.fr
}

\begin{abstract}
Photoreflectance spectroscopy is applied on tensilely-strained silicon on insulator (sSOI) thin layers in order to evaluate the biaxial strain effect on the Si direct bandgap. The measured redshift of the $E_{0}^{\prime}$ transition (i.e. direct bandgap) with strain $(\sim-100 \mathrm{meV} / \%)$, corresponds to theoretical predictions. The hydrostatic and valence band deformation potential parameters for $\mathrm{E}_{1}$ (i.e. transition close to L-point along the $\Lambda$-direction) are also measured: $D_{1}^{1}=-7.5 \pm 0.5 \mathrm{eV}$ and $\left|D_{3}^{3}\right|=3.8 \pm 1 \mathrm{eV}$.
\end{abstract}

Keywords: Photoreflectance ban, strained Si, sSOI, Si direct bandgap.

PACS: 71.70.Fk, 78.20.-e, 78.30.-j, 78.40.Fy 


\section{Introduction}

Stress modification of Si optical properties is a long-standing topic studied since more than 40 years [1]. This fundamental subject is revived by recent publications on strained $\mathrm{Si}(\mathrm{sSi})$ thin films for application in microelectronics and optoelectronics fields [2,3]. Considering microelectronics, Metal Oxide Semiconductor (CMOS) devices display improved electrical performances with respect to bulk $\mathrm{Si}$ [1] thanks to electrons and holes mobility enhancement caused by strain induced band structure modification. For a biaxial tensile strain induced in the Si layers, the conduction band minima $\left(\Delta_{6}\right)$ split in the $\Delta$-direction into $\left(\Delta_{4}\right)$ and $\left(\Delta_{2}\right)$ valleys. Similarly, the degeneracy of light holes $(\mathrm{LH})$ and heavy holes $(\mathrm{HH})$ valence bands at $\Gamma$-point is lifted by biaxial strain. As a consequence, Si indirect bandgap shrinkage is caused. This effect, predicted by theoretical calculations $[4,5]$ has been confirmed by photoluminescence (PL) spectroscopy for a thick strained Si layer on oxidized porous $\mathrm{Si}$ [6] and recently for ultrathin sSi layers on insulator [7]. Nevertheless, experimental knowledge of biaxial tensile strain effects on interband critical points (CP) at higher energy (2-5 eV) is still lacking for thin sSi layers which cannot be measured by PL.

Many works have reported optical measurements on compressive uniaxial stress on bulk Si using electroreflectance [8,9] and photoreflectance (PR) [10] spectroscopy, spectroscopic ellipsometry [11,12], or reflectance anisotropy spectroscopy [13]. According to the Si crystal symmetry, compressive uniaxial stress and tensile biaxial strain may have the same effect on the band structure. Nevertheless, Anastassakis et al. have pointed out that under uniaxial stress, applied externally to samples, a stress relaxation may occur near the surface [14]. Lee and Jones, have measured the dielectric constant by ellipsometry for a thin Si layer grown on relaxed $\mathrm{Si}_{0.895} \mathrm{Ge}_{0.115}$ thick layer and found some discrepancies in the dielectric function variation in comparison to bulk Si samples under uniaxial stress [15]. These discrepancies, more pronounced around the $\mathrm{E}_{2}$ transition are attributed to uncertainties in the elasto-optic constants determined on uniaxially stressed samples. More recently, Vineis [16] checked this point by performing spectroscopic ellipsometry on a sSi epitaxial layer deposited on a $\mathrm{Si}_{0.81} \mathrm{Ge}_{0.19}$ virtual substrate (VS). Nevertheless, the equivalent stress in the sample was supposed to be $1.3 \mathrm{GPa}$ but was not measured and only a single strain value (one sample) was used. Finally, Wong et al. have found a 
good agreement between strain values measured by spectroscopic ellipsometry using deformation potential from literature and by Raman Spectroscopy [17]. In a previous work [18], we have reported PR measurements on a strained Si quantum well deposited on a SGOI (SiGe on Insulator) substrate and we obtained similar results as Vineis. In this paper, in order to complete previous studies we have determined pair band deformation potentials in the case of biaxial strain on thin Si layers. Toward this end, we applied PR spectroscopy to a series of pseudomorphic strained Si-On-Insulator (sSOI) substrates with various strain values.

\section{Experimental details}

The strain in the $\mathrm{Si}$ layers is induced from a relaxed $\mathrm{Si}_{1-\mathrm{x}} \mathrm{Ge}_{\mathrm{x}}$ template layer. The relaxed $\mathrm{Si}_{1-\mathrm{x}} \mathrm{Ge}_{\mathrm{x}}$ layer [19] is grown on top of a linearly graded $\mathrm{Si}_{1-\mathrm{w}} \mathrm{Ge}_{\mathrm{w}}$ layer $(2 \%<\mathrm{w}<20 \%, 30 \%$ or $40 \%)$ on $\mathrm{Si}(001)$ substrate. The germanium in the constant composition $\mathrm{Si}_{1-\mathrm{x}} \mathrm{Ge}_{\mathrm{x}}$ layer is varied between $20 \%, 30 \%$ or $40 \%$, subsequently a Si layer is grown on top, thus, a strain is induced in these overgrown layers. The strained Si layer thickness is 15 , 20 and $24 \mathrm{~nm}$ for the samples labeled sSi20, sSi30 and sSi40 respectively. The sSi layer as well as a few hundreds of nm of $\mathrm{Si}_{1-\mathrm{x}} \mathrm{Ge}_{\mathrm{x}}$ layer are then transferred on a Si handle wafer by the Smart $\mathrm{Cut}^{\mathrm{TM}}$ process in order to obtain a $\mathrm{SiGe} / \mathrm{sSi} / \mathrm{SiO}_{2} /$ substrate $\mathrm{Si}$ structure [20]. Finally, a selective etching of the SiGe layer leads to a sSOI substrate, as is shown in the figure 1.

In order to realize the PR measurements, we used a probe beam from a $150 \mathrm{~W}$ quartz tungsten halogen lamp dispersed through a monochromator. The modulated electric field in the sample is obtained from a $244 \mathrm{~nm}$ line which is used as the pump beam, this beam laser is chopped at $110 \mathrm{~Hz}$. Thus, the reflected light from the sample surface is detected by a GaAs photomultiplier. The detection range of this photomultiplier is between $300 \mathrm{~nm}$ to $900 \mathrm{~nm}$. The modulated part of the reflectance signal is extracted by a lock-in amplifier. Photoreflectance can be classified into low and high electrical field regimes, depending on the relative strengths of the electro-optic energy as compared to the broadening of the PR transitions. In the low electric field regime, the modulation $\Delta \varepsilon$ of the dielectric function $\varepsilon$ has a line shape that is the Third Derivative Functional Form (TDFF) of the unperturbed dielectric function. However at high field the PR spectrum exhibits an oscillatory behavior [the so-called Franz-Keldysh oscillations (FKO)]. We do not observe the oscillations FKO in our 
spectra and we thus limit our discussion to the low electrical field. The differential changes in the reflectivity $\mathrm{R}$ are related to the perturbation of the complex dielectric function $\Delta \varepsilon$ by the Seraphin equation [21]:

$$
\frac{\Delta R}{R}=a \Delta \varepsilon_{1}+b \Delta \varepsilon_{2}
$$

where $a$ and $b$ are the Seraphin coefficients and $\varepsilon_{1}$ and $\varepsilon_{2}$ are the real and imaginary parts of the dielectric function $\varepsilon$. In most cases, near the fundamental gap of bulk materials, coefficient $b$ is very small and the second term in Eq. (1) can be neglected in such a way that $\Delta R / R$ is proportional to the modulation of the real part of the dielectric function $\Delta \varepsilon_{1}$.

If the form of $\varepsilon_{l}$ is a generalized TDFF, which is our case, the $\Delta R / R$ takes a particularly form proposed by Aspnes [22]:

$$
\frac{\Delta R}{R}=\operatorname{Re}\left[A \exp (i \phi)\left(E-E_{g}+i \Gamma\right)^{-m}\right]
$$

where $A$ is the signal amplitude, $\Gamma$ the line broadening, $E g$ the energy of the investigated critical point $(\mathrm{CP})$ in the combined density of states and $E$ the incident photon energy. $\phi$ is a phase factor and $m$ varies between 2.5 and 3.5, depending on the CP dimension.

We carried out Raman measurements in order to evaluate the induced strain in the Si thin layers. The measurements were carried out under a microscope in a back scattering configuration with a monochromator. We used a $363 \mathrm{~nm}$ line as the excitation source in order to excite only the sSi thin layer. The laser is absolutely absorbed by the strained Si layers because of the $363 \mathrm{~nm}$ line penetration depth is between 10 and $20 \mathrm{~nm}$ which is determined by optic constants of silicon [23,24]. This UV line is almost resonant with the Si direct bandgap and the sSi signal is enhanced. In order to avoid any laser induced local heating effects in the sSi layers a low power setting $(<0.1 \mathrm{~mW})$ for the $1 \mu \mathrm{m}$ in diameter incident laser beam was adopted 


\section{Results and discussion}

\subsection{Strain evaluation}

The figure 2 shows the Raman spectra for the sSOI samples under UV excitation, a comparison with a bulk Si reference is done also. The spectra shows the Raman peaks from the sSi layers at $513.3 \mathrm{~cm}^{-1}, 510.6 \mathrm{~cm}^{-}$ ${ }^{1}$ and $508.9 \mathrm{~cm}^{-1}$ for the $\mathrm{sSi} 20, \mathrm{sSi} 30$ and $\mathrm{sSi} 40$ samples, respectively, the frequency is reduced with respect to the Raman peak from the Si reference $\left(519.3 \mathrm{~cm}^{-1}\right)$ as the strain nominal values is increased. Thus, the shift induced by the strain $(\Delta \omega)$ between sSOI sample and Si bulk peaks in the Raman analysis reveals $6.0 \mathrm{~cm}^{-1}, 8.7 \mathrm{~cm}^{-1}$ and $10.4 \mathrm{~cm}^{-1}$ for the sSi20, sSi30 and sSi40 samples, respectively. The biaxial in-plane strain, $\varepsilon_{\|}$, can be then deduced by the following expression: $\varepsilon_{\|}(\%)=c \Delta \omega\left(\mathrm{cm}^{-1}\right)$. A $c$ parameter value of $0.138 \mathrm{~cm}$ is calculated from the phonon deformation potential theory [25]. This theoretical parameter is close to the $0.133 \mathrm{~cm}$ experimental value found by Erdtmann et al. [26] which was obtained by a direct correlation between X-ray diffraction and Raman measurements on sSOI structures. Taking into account this uncertainty in $c$ parameter $(0.133$ or 0.138$)$ we extracted strain values $0.81 \pm 0.015 \%, 1.18 \pm 0.02 \%$ and $1.41 \pm 0.03 \%$ for the sSi $20, \mathrm{sSi} 30$ and sSi40 samples, respectively. The strain value for the sSi40 sample is found to be lower than the expected value (1.6\%). This is due to the sample thickness which is larger than the critical one which is around $7 \mathrm{~nm}$ for this strain value [27].

\subsection{Strain effect on Si direct bandgap and high energy critical points}

In order to evaluate the strain effect on the Si direct bandgap, we performed the PR measurements at room temperature for sSi20, sSi30, sSi40 samples and bulk reference $\mathrm{Si}$, these spectra are shown in figure 3 . The TDFF fit carried out on the bulk Si spectrum exhibits two transitions which are reported in table 1. The first transition at $3.33 \mathrm{eV}$, is related to $E_{0}$ ' critical point, this transition takes place between the top of the valence band in the unstrained Si and the minimum of the conduction band at $\Gamma$ point. This energy value is in agreement with the Si direct bandgap at room temperature according to literature results [11,28]. The transition at $3.45 \mathrm{eV}$ is related to $E_{l}$ critical point which takes place between the valence and conduction bands along the $\Lambda$-direction close to L-point in bulk Si $[29,30]$. On the other hand, three transitions were deduced from TDFF fit for the 
spectra of sSi layers. It is clearly that the induced strain in the Si layers affects the interband critical points since two transitions are only observed in the bulk Si. The three transitions are reported in Table 1 . It is worth noting that the spectra around $3.8 \mathrm{eV}$ are noisier because of the detection limit at $300 \mathrm{~nm}$ and a lower signal is obtained, thus, when we derivate the $\Delta \mathrm{R}$ the noise increases. Let us consider first the transition $E_{0}^{\prime}$ for the three samples. This transition takes place between the bottom of the conduction band at $k=0$ and the maxima of light hole $(l h)$ valence band (i.e. sSi direct bandgap, $E_{g}$ ). From Raman and PR measurements, we obtain an experimental strain dependence of sSi direct band gap (figure 4). This experimental dependence is compared to the theoretical curve $E g$ vs $\varepsilon_{\|}$obtained from the following expression [8]:

$$
\begin{gathered}
E_{g}=E_{0}^{\prime}+a\left(\varepsilon_{\perp}+2 \varepsilon_{l l}\right)+\frac{\Delta_{0}}{2}-\frac{1}{4} \delta E_{100}-\frac{1}{2} \sqrt{\Delta_{0}^{2}+\Delta_{0} \delta E_{100}+\frac{9}{4}\left(\delta E_{100}\right)^{2}} \\
\text { with } \delta E_{100}=2 b\left(\varepsilon_{\perp}-\varepsilon_{l l}\right)
\end{gathered}
$$

where $E_{g}$ is the sSi band gap at $\Gamma$ point. $E_{0}^{\prime}=3.345 \mathrm{eV}$ is the direct band gap of unstrained $\mathrm{Si}$ at room temperature without spin-orbit splitting, $\varepsilon_{||}$and $\varepsilon_{\perp}$ are the in-plane and perpendicular strain respectively, $a=$ $0.48 \mathrm{eV}$ and $b=-2.35 \mathrm{eV}$ are the hydrostatic and shear deformation potentials parameters of Si respectively [28] and $\Delta_{0}=0.044 \mathrm{eV}$ is the spin-orbit splitting. As can been observed from figure 4, a very good correlation between experimental points and theoretical curve is obtained bearing out the values calculated by Van de Walle [31].

According to theoretical biaxial strained Si band structure [4], the transitions at higher energy are attributed to the split induced by the strain in the $E_{l}$ transition which takes place along the $\Lambda$-direction. Thus, two transitions $E_{l}(1)$ and $E_{l}(2)$ are observed as previously they were reported [10]. We observed for the sample sSi20 a transition at $3.37 \mathrm{eV}$ which is related to $E_{l}(1)$ transition and the second one $\left(E_{l}(2)\right)$ is deduce at $3.44 \mathrm{eV}$ which are in a good agreement with respect to the Ref. 16, where they reported two transition energies for a sample equivalent to $\mathrm{sSi} 20$ at $3.309 \mathrm{eV}$ and $3.437 \mathrm{eV}$ (see table 1). The biaxial strain dependence of $E_{l}(1)$ and $E_{l}(2)$ 
transitions is given using the following equations which are derived for uniaxial stress theory, ignoring spin-orbit splitting effects [16]:

$$
\begin{aligned}
& E_{1}(1)=E_{1}+\frac{2 D_{1}^{1}}{\sqrt{3}}\left(S_{11}+2 S_{12}\right) \frac{E \varepsilon_{l l}}{(1-v)}+\sqrt{\frac{2}{3}} D_{3}^{3}\left(S_{11}-S_{12}\right) \frac{E \varepsilon_{l l}}{(1-v)} \\
& E_{1}(2)=E_{1}+\frac{2 D_{1}^{1}}{\sqrt{3}}\left(S_{11}+2 S_{12}\right) \frac{E \varepsilon_{l l}}{(1-v)}-\sqrt{\frac{2}{3}} D_{3}^{3}\left(S_{11}-S_{12}\right) \frac{E \varepsilon_{l l}}{(1-v)}
\end{aligned}
$$

where $E_{1}$ is the energy gap for unstrained $\mathrm{Si}, D_{1}^{1}$ and $D_{3}^{3}$ are respectively the hydrostatic and valence band deformation potential parameters [10], $S_{11}$ and $S_{12}$ are the compliance constants, given by $S_{11}=\left(C_{11}+C_{12}\right) /\left(C_{11}-C_{12}\right)\left(C_{11}+2 C_{12}\right)$ and $S_{12}=-C_{12} /\left(C_{11}-C_{12}\right)\left(C_{11}+2 C_{12}\right)$ with $C_{11}=167.5 \mathrm{GPa}$ and $C_{12}=65 \mathrm{GPa}$ the elastic constants of Si. $E$ and $v$ are the Young modulus and Poisson ratio of Si, respectively. A linear fit was used for $E_{l}(1)$ and $E_{l}(2)$ data (see figure 4). Thus, we obtained $D_{1}^{1}=-7.5 \pm 0.5 \mathrm{eV}$ and $\left|D_{3}^{3}\right|=3.8 \pm 1 \mathrm{eV}$ values from equations (4) and (5). These deformation potential parameters for biaxial strain agree well with previously reported ones for uniaxial stress [10] $\left(D_{1}^{1}=-8 \mathrm{eV}\right.$ and $\left.D_{3}^{3}=5 \mathrm{eV}\right)$.

\section{Conclusions}

Photoreflectance spectroscopy was used to quantify the impact of biaxial tensile strain on the silicon direct bandgaps in sSOI structures at room temperature. The $E_{0}^{\prime}$ (i.e. direct $\left.E_{g}\right), E_{l}(1)$ and $E_{l}(2)$ transitions between the valence and conduction bands in the $\Gamma$-point and along of the $\Lambda$-direction, respectively, were obtained in sSOI $20 \%$, sSOI $30 \%$ and sSOI $40 \%$ samples. The measurements confirmed theoretical calculations of strain induced direct bandgap shrinkage in sSi. Deformation potential for $\mathrm{E}_{1}$ transitions was shown to be closed to previous reports for uniaxial stress. The expected equivalence between uniaxial stress on bulk Si samples and biaxial strain in sSOI are then demonstrated. 


\section{Acknowledgment}

This work was partially supported by the CONACYT grant program and the MEDEA 2T 101 within the frame of a CEA-LETI / INL collaboration. The authors thank CEA/LETI and SOITEC for sample preparation. 


\section{Figure Captions}

Figure 1: Smart Cut layer transfer concept applied to the realization of strained silicon on insulator wafer.

Figure 2: $\quad$ Raman spectra of thin strained Si layers (sSi20, sSi30 and sSi40 samples) as well as reference bulk Si under UV resonant excitation $(363 \mathrm{~nm})$. The tensile strain induced Raman shifts are materialised by horizontal arrows.

Figure 3: $\quad$ Measured photoreflectance spectra of thin strained Si layers (sSi20, sSi30 and sSi40 samples) as well as bulk Si at room temperature. Transition energies deduced from TDFF fits are indicated on the spectra.

Figure 4: Si direct band gap $E_{g}$, and $E_{l}(1)$ and $E_{l}(2)$ transition energies deduced from PR results as a function of the in-plane strain (sSi20, sSi30, sSi40 samples and bulk Si reference). Dotted and dash-dotted lines are linear fits to $E_{l}(1)$ and $E_{l}(2)$ respectively. The solid line is the theoretical strain dependence of $E_{0}^{\prime}$ obtained from equation (2). 
Figure 1

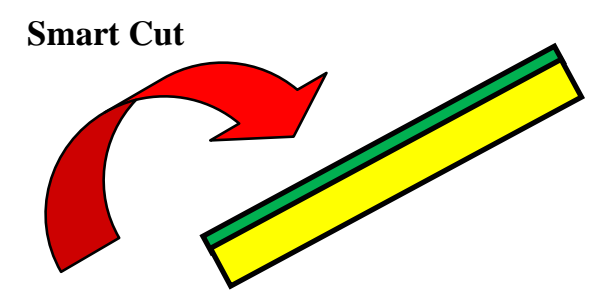

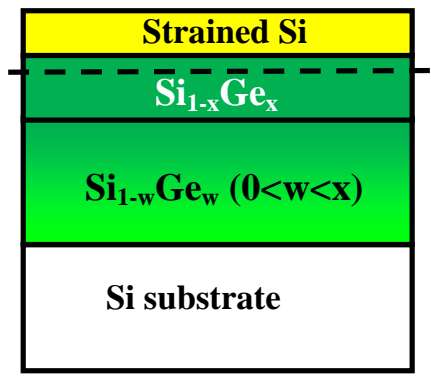

Starting material

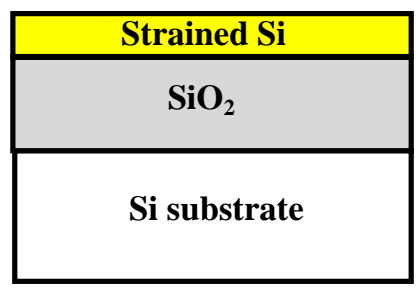

Final structure on insulator 
Figure 2

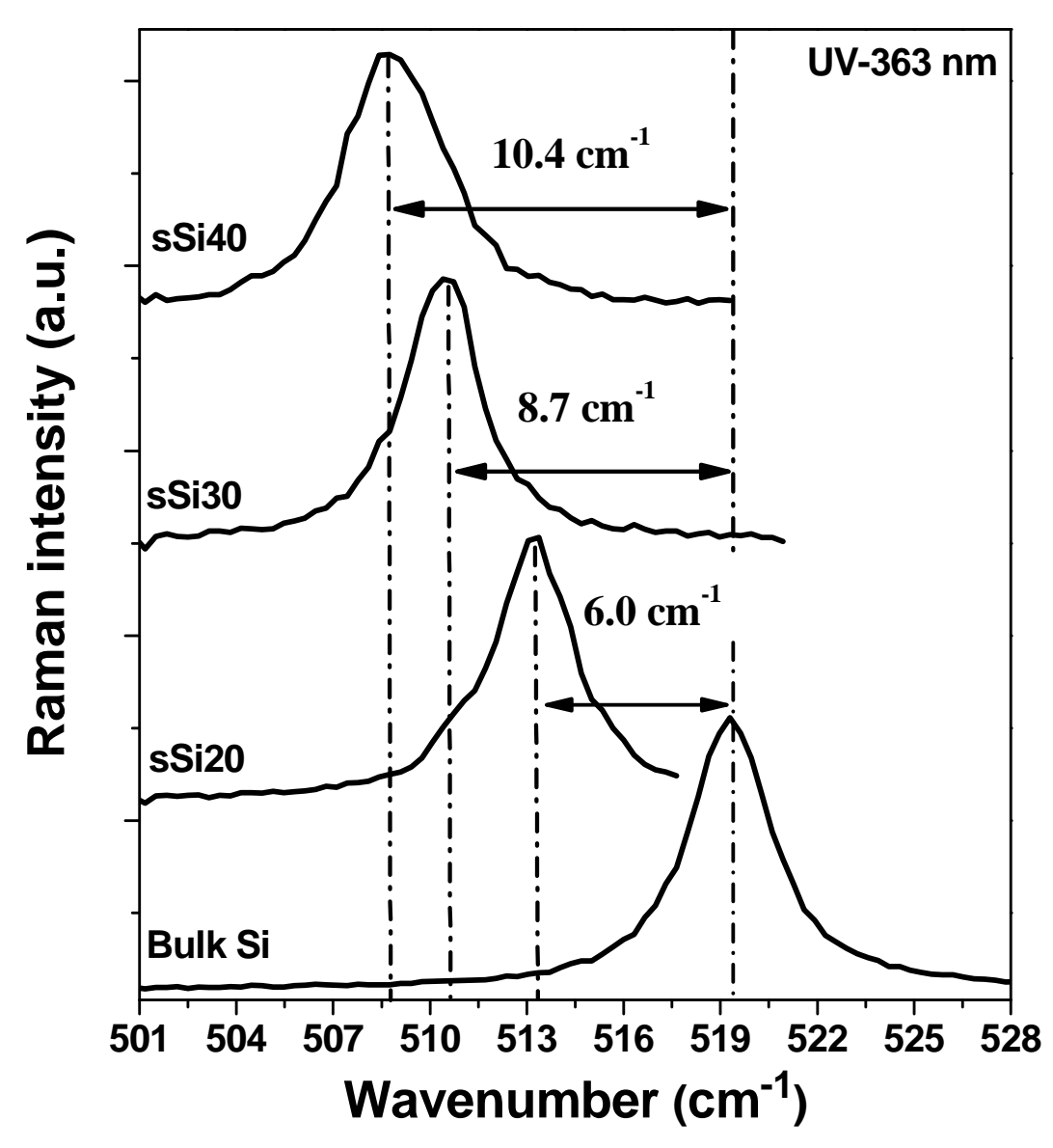


Figure 3

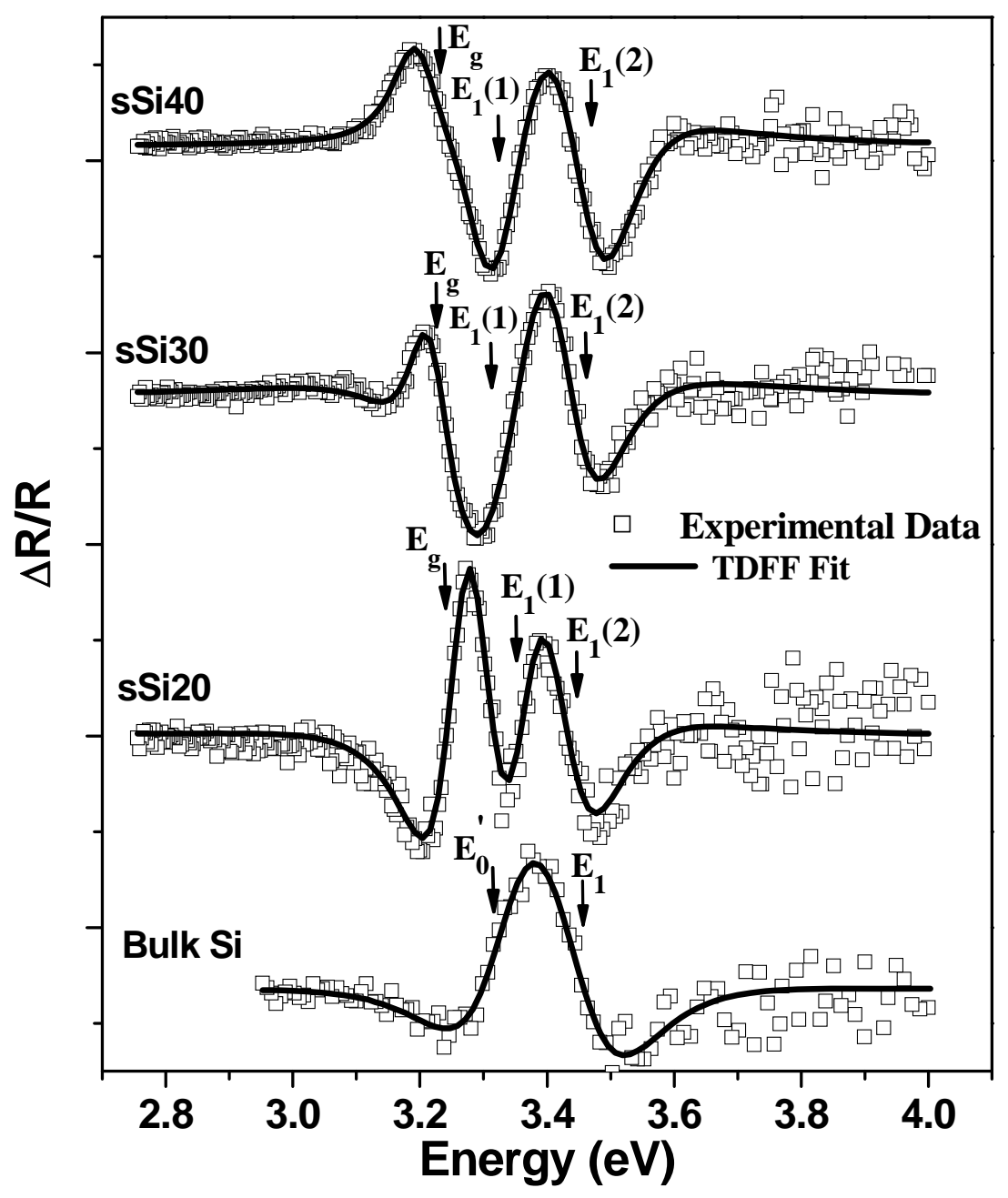


Figure 4

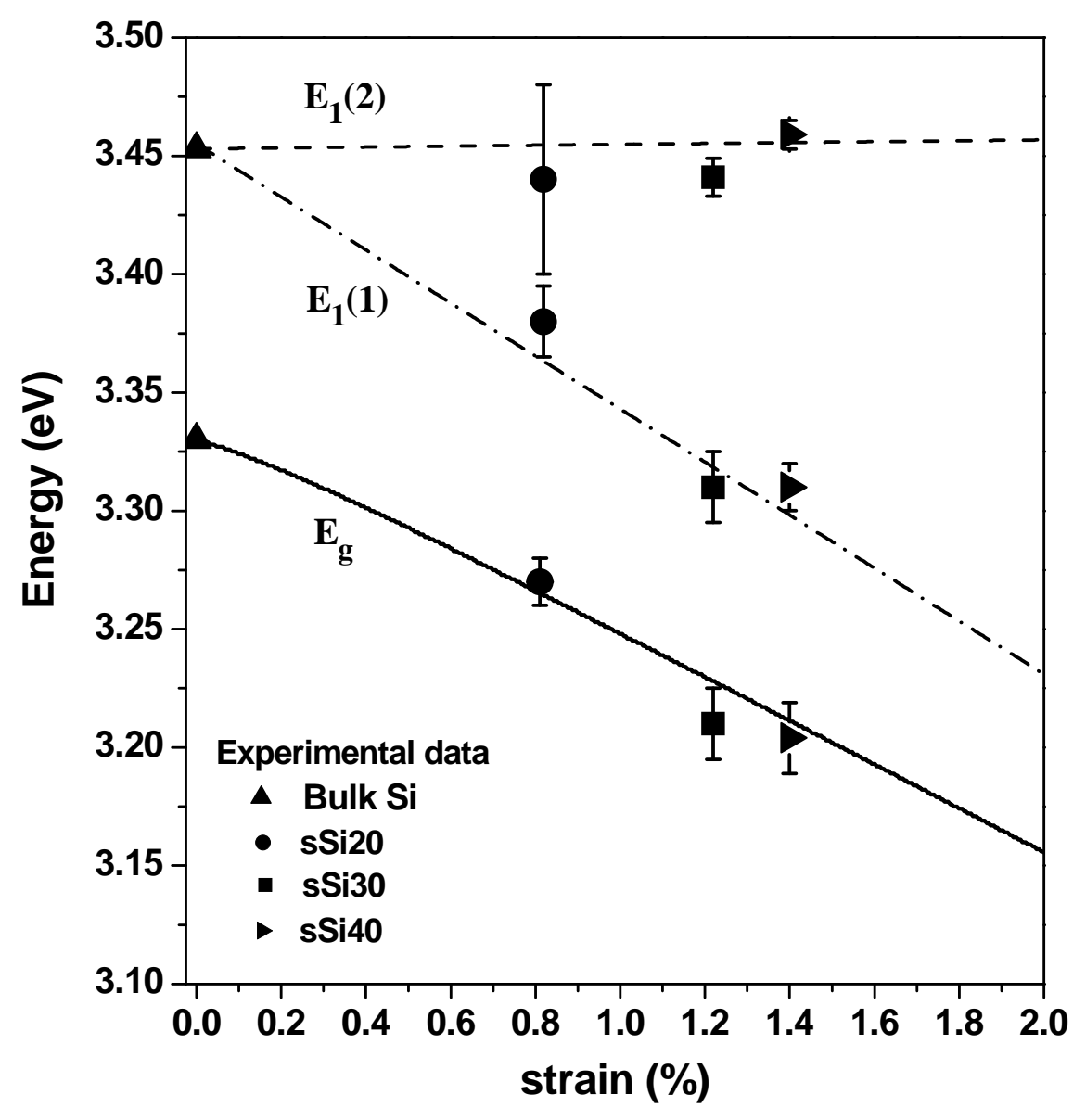


Table 1: $\quad$ Measured transition energy for bulk $\mathrm{Si}$ and strained samples in the 3-4 eV range. ${ }^{\text {a }}$ This work using photoreflectance spectroscopy, ${ }^{\mathrm{b}}$ values from reference [16] obtained from spectroscopic ellipsometry. The strained sample used in reference [16] is considered as equivalent to sSi20.

\begin{tabular}{|c|c|c|c|c|c|c|}
\hline & $E_{0}^{\prime a}(e V)$ & $E_{0}^{\prime b}(e V)$ & $E_{1}(1)^{a}(e V)$ & $E_{1}(1)^{b}(e V)$ & $E_{1}(2)^{a}(e V)$ & $E_{1}(2)^{b}(e V)$ \\
\hline Bulk Si & 3.33 & 3.311 & 3.45 & 3.398 & & \\
\hline sSi20 & 3.27 & 3.327 & 3.37 & 3.309 & 3.44 & 3.437 \\
\hline sSi30 & 3.21 & & 3.31 & & 3.44 & \\
\hline sSi40 & 3.20 & & 3.31 & & 3.46 & \\
\hline
\end{tabular}




\section{References.}

[1]. G.W. Gobeli and E.O. Kane, Phys. Rev. Lett. 15, 142 (1965).

[2]. T. M. Currie, C. W. Leite, T. A. Langdon, G. Taraschi, E. A. Fitzgerald, D. A. Antonaidis, J. Vac. Sci. Technol. B 19, 2268 (2001).

[3]. R.S. Jacobsen, K. Andersen, P.I. Borel, J. Fage-Pedersen, L.H. Frandsen, O. Hansen, M. Kristensen, A.V. Lavrinenko, G. Moulin, H. ou, C. Peucheret, B. Zsigri and, A. Bjarklev, Nature 441, 199 (2006).

[4]. S. Richard, F. Aniel, G. Fishman, N. Cavassilas, J. Appl. Phys. 94, 1795 (2003).

[5]. L. Yang J. R.Watling, R. C W Wilkins, M. Boriçi, J. R Barker, A. Asenov, S. Roy, Semicond. Sci. Technol. 19, 1174, (2004).

[6]. O. Marty, T. Nychyporuk, J. de la Torre, V. Lysenko, G. Bremond and D. Barbier, Appl. Phys. Lett. 88, 101909-1 (2006).

[7]. J. Munguía, G. Bremond, J. de la Torre and J-M. Bluet, Appl. Phys. Lett. 90, 042110 (2007).

[8]. F. H. Pollak and M. Cardona, Phys. Rev. 172, 816 (1968)

[9]. K. Kondo and A. Moritani, Phys. Rev. B 14, 1577 (1976).

[10]. F. H. Pollak, G. W. Rubloff, Phys. Rev. Lett. 29, 789 (1972)

[11]. P. Lautenschlager, M. Garriga, L. Viña, M. Cardona, Phys. Rev. B 36, 4821 (1987)

[12]. P. Etchegoin, J. Kircher and M. Cardona, Phys. Rev. B 47, 10292 (1993)

[13]. D. Papadimitriou and W. Richter, Phys. Rev. B 72, 075212 (2005).

[14]. E. Anastassakis, Y.S. Raptis, M. Hünermann, W. Ruchter and M. Cardona, Phys. Rev. B 38, 7702 (1988).

[15]. H. Lee and E.D. Jones, Appl. Phys. Letter 68 (22), 3153 (1996).

[16]. C. J. Vineis, Phys. Rev. B 71, 245205 (2005).

[17]. T.K.S. Wong, Y. Gong, P. Yang and C.M. Ng, Semicond. Sci. Technol. 22, 1232 (2007).

[18]. J. Munguía, G. Bremond, O. Marty and J-M. Bluet, M. Mermoux, Appl. Phys. Letter, 91, 122108 (2007).

[19]. J. M. Hartmann, A. Abbadie, D. Rouchon, J. P. Barnes, M. Mermoux, T. Billon, Thin Sol. Films, 516, $4238(2008)$. 
[20]. B. Ghyselen, J.-M. Hartmann, T. Ernst, C. Aulnette, B. Osternaud, Y. Bogumilowicz, A. Abbadie, P. Besson, O. Rayssac, A. Tiberj, N. Daval, I. Cayrefourq, F. Fournel, H. Moriceau, C. Di Nardo, F. Andrieu, V. Paillard, M. Cabie, L. Vincent, E. Snoeck, F. Cristiano, A. Rocher, A. Ponchet, A. Claverie, P. Boucaud, M.-N. Semeria, D. Bensahel, N. Kernevez and C. Mazure, Solid State Electron. 48, 1285 (2004).

[21]. B. O. Seraphin and N. Bottaka, Phys. Rev. 145, 628 (1966).

[22]. D. E. Aspnes, Surface Science, 37, 418 (1973).

[23]. G. E. Jellison, F. A. Modine, J. Appl. Phys. 53, 3745 (1982).

[24]. D. E. Aspens, A. A. Studna, Phys. Rev. B. 27, 985 (1983).

[25]. E. Anastassakis, A. Pinczuk, E. Burstein, F. H. Pollak, M. Cardona, Solid State Comm. 8, 133, (1970).

[26]. M. Erdtmann, T. A. Langdon, J. Mater. Sci: Mater. Electron. 17, 137 (2006).

[27]. A. Lochtefeld., Mater. Sci. Engine. 135, 228 (2006).

[28]. M. Cardona, K. L. Shaklee, F. H. Pollak, Phys. Rev. 154, 696 (1967).

[29]. R. R. L. Zucca, Y. R. Shen, Phys. Rev. B 1, 2668 (1970).

[30]. E. Matatagui, A. G. Thompson, M. Cardona, Phys. Rev. 176, 950 (1968).

[31]. C. G. Van de Walle, Phys. Rev. B 39, 1871 (1989). 